\title{
Properties of Extract Obtained from Defatted Rice Bran by Extraction with Aqueous
}

\section{Ethanol under Subcritical Conditions}

\author{
Tai-Ying Chiou, Tze Loon Neoh, Takashi Kobayashi and Shuji Adachi \\ Division of Food Science and Biotechnology, Graduate School of Agriculture, Kyoto University, Sakyo-ku, Kyoto 606-8502, Japan
}

Received May 23, 2011; Accepted October 21, 2011

Defatted rice bran was treated with water or aqueous ethanol under subcritical conditions to recover materials with antioxidative activity. The extraction conditions, namely ethanol concentration $(10-100 \%$ $(\mathrm{v} / \mathrm{v}))$, temperature $\left(120-237^{\circ} \mathrm{C}\right)$ and time after attainment of a desired temperature $(5-60 \mathrm{~min})$, were studied. On the basis of the determinations of total carbohydrate, protein and phenolic contents, yield, DPPH radical scavenging activity, and antioxidative activity against oxidation of bulk linoleic acid, the extraction with $20 \%(\mathrm{v} / \mathrm{v})$ ethanol at $237^{\circ} \mathrm{C}$ for 5 min was concluded to be comparatively more efficient than that by subcritical water at the same extraction temperature for the same length of time.

Keywords: defatted rice bran, extraction, subcritical water, antioxidative activity, ethanol

\section{Introduction}

Rice bran (Oryza sativa) is a byproduct from the rice milling or polishing process of brown rice to produce more visually appealing white rice. In Japan, about 0.88 million tons of rice bran are produced every year, which accounts for approximately $10 \%$ of the annual rice production of the country. Defatted rice bran finds uses in animal feeds and fertilizers, but still most of it is discarded as an agricultural waste. Despite its considerable contents of several useful substances, this resource has yet to be fully utilized. The dietary fiber from defatted rice bran was found to exhibit higher water-binding, fat-binding, and emulsifying capacities than that from sugar beet (Abdul-Hamid and Luan, 2000). Defatted rice bran also contains phenolic compounds that have antioxidative (Cuvelier et al., 1992; Graf, 1992), ultraviolet absorbing (Castelluccio et al., 1995), and anti-tumor activities (Han et al., 2001). Several extraction methods, namely the extraction by organic solvents such as methanol (Iqbal et al., 2005), ethanol (Kaneda et al., 2004), and acetone (Chung and Woo, 2001) and non-organic solvents such as supercritical carbon dioxide (Kim et al., 1999), have been the subject of study to recover these functional substances. The organic solvent extraction is a time consuming process and the extensive use of organic solvents also causes pol-

*To whom correspondence should be addressed.

E-mail: adachi@kais.kyoto-u.ac.jp lution. Likewise, the treatment with supercritical carbon dioxide involves a great amount of carbon dioxide which is a predominant anthropogenic greenhouse gas. On the contrary, subcritical water treatment provides an environmentally friendly option for effective extraction of functional substances from food and agricultural wastes (Hata et al., 2008; Pourali et al., 2009; Watchararuji et al., 2008; Wiboonsirikul et al., 2007a; 2007b).

Subcritical water is water at over $100^{\circ} \mathrm{C}$ that is compressed to maintain its liquid state below the critical point. The dielectric constant of water decreases from 80 to 27 with heating from room temperature to $250^{\circ} \mathrm{C}$, which is similar to that of ethanol under ordinary pressure (Herrero et al., 2006; Miller and Hawthorne, 2000). At high temperatures, the substantially increased ion product of subcritical water is beneficial as an extractant or catalyst to hydrolyze biomass such as protein (Rogalinski et al., 2005) and carbohydrate (Khajavi et al., 2006) without the need of other additional catalysts. Subcritical water could hydrolyze cellulose (Sasaki et al., 1998; 2000). We have also reported that substances with antioxidative, radical scavenging, and emulsifying activities were extracted from rice bran by subcritical water treatment (Hata et al., 2008; Wiboonsirikul et al., 2007a; 2007b; 2008a; 2008b).

In order to find conditions for more effective recovery of useful substances from defatted rice bran, extraction with aqueous ethanol was examined under subcritical condi- 
tions. We denoted the treatment under subcritical conditions simply as extraction though the treatment may also involve other reactions such as degradation and hydrolysis. To the best of our knowledge, there are only a limited number of published studies available at the present time concerning the extraction system utilizing compressed water-organic solvent mixtures of high temperatures as extraction mediums. In this study, we selected ethanol as the organic solvent on the basis of economic and safety concerns. The critical point of ethanol is $241^{\circ} \mathrm{C}, 6.33$ to $6.39 \mathrm{MPa}$ (Gude and Teja, 1995). From Dalton's law of partial pressures and Antoine's equation (Ambrose et al., 1975), the pressure of $20 \%$ (v/v) aqueous ethanol at $237^{\circ} \mathrm{C}$ is estimated to be approximately 3.37 $\mathrm{MPa}$, approximating that of water at $3.19 \mathrm{MPa}$. Although the hydrothermal oxidation causes ethanol to decompose, the conversion of ethanol would be low without the presence of oxidizers (Hirosaka et al., 2007; 2008).

The objective of this study is to examine the effect of addition of ethanol on the efficiency of extraction under subcritical conditions, aiming at developing a new extraction module for further applications.

\section{Materials and Methods}

Materials Rice bran (Oryza sativa), defatted by Soxhlet extraction using petroleum ether according to the official method of AOCS Ba 3-38 (AOCS, 1979), was supplied by Tsuno Food Industrial (Wakayama, Japan). Gallic acid was purchased from Sigma-Aldrich Japan (Tokyo, Japan), linoleic and ferulic acids were from Tokyo Chemical Industry (Tokyo, Japan), and Folin and Cioculteu's phenol reagent was from ICN Biomedicals (Aurora, OH, USA). L-Ascorbic acid (abbreviated as VC, purity $>99.5 \%$ ), sodium hydroxide $(\mathrm{NaOH})$, and sodium carbonate $\left(\mathrm{Na}_{2} \mathrm{CO}_{3}\right)$ were purchased from Nacalai Tesque (Kyoto, Japan). Crystallized bovine serum albumin (BSA, 99\% purity), 1,1-diphenyl-2-picryhydrazyl (DPPH), and all other chemicals of reagent grade or higher were obtained from Wako Pure Chemical Industries (Osaka, Japan). Distilled water was used throughout the entire experiment.

Preparation of defatted rice bran extracts Subcritical extraction was performed in a TVS-N2 type SUS-316 stainless steel vessel (Taiatsu Techno, Osaka, Japan) with a working volume of $117 \mathrm{~mL}$ (30 mm i.d. $\times 165.5 \mathrm{~mm}$ height). The vessel is resistant to pressures of up to $20 \mathrm{MPa}$. The extraction procedure was to a great extent similar to that reported by Hata et al. (2008). The extraction was carried out at a weight ratio of extraction medium to defatted rice bran of 50 . Briefly, $1.5 \mathrm{~g}$ of defatted rice bran was accurately weighed into the vessel. Then, $75 \mathrm{~mL}$ of the extraction medium, which was earlier degassed by sonication, was added. The vessel

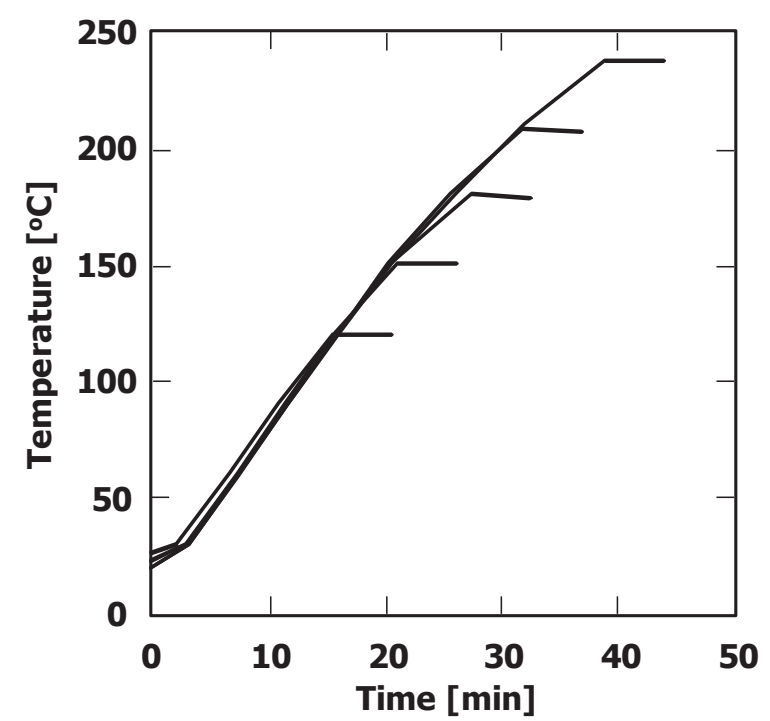

Fig. 1. Temperature time courses of the extraction vessel during extraction using $20 \%(\mathrm{v} / \mathrm{v})$ aqueous ethanol as the extraction medium.

was tightly closed and heated in a mantle heater (TXN-700B, As One, Osaka, Japan) to reach the desired extraction temperature and held for a prescribed extraction time. Figure 1 shows the temperature time courses of the subcritical extraction treatment using $20 \%(\mathrm{v} / \mathrm{v})$ aqueous ethanol at different extraction temperatures for an extraction time of $5 \mathrm{~min}$. The crude extract was filtered under vacuum suction through a $0.8 \mu \mathrm{m}$ cellulose acetate membrane filter (Advantec Toyo, Tokyo, Japan). The extracts were kept at $5^{\circ} \mathrm{C}$ until further analyses.

$U V$-Vis spectra of defatted rice bran extracts The absorbance spectra of the defatted rice bran extracts versus their respective extraction mediums as the blanks were recorded on a Shimadzu UV-1600 spectrophotometer (Kyoto, Japan) in the wavelength range of 200 to $500 \mathrm{~nm}$. The extracts were diluted 100 times with water prior to measurement.

HPLC of defatted rice bran extracts Ten microliters each of the defatted rice bran extracts obtained by using water and 20\% (v/v) aqueous ethanol were analyzed separately by HPLC using a Shimadzu LC-1-AD VP pump through a YMC-pack Hydrosphere C18 column (150 mm $\times 3.0 \mathrm{~mm}$ i.d.; Kyoto, Japan). The HPLC system was equipped with a Shimadzu SPD-10AV VP UV-Vis detector for detection of absorbance at $280 \mathrm{~nm}$. Elution was achieved by a gradient of distilled water to methanol in $50 \mathrm{~min}$ at a flow rate of 0.5 $\mathrm{mL} / \mathrm{min}$. Isocratic elution of $100 \%$ distilled water for $10 \mathrm{~min}$ and $100 \%$ methanol for $20 \mathrm{~min}$ were introduced before and after the 50-min gradient program, respectively.

Total carbohydrate content The total carbohydrate content was evaluated by the method based on the phenolsulfuric acid reaction (Dubois et al., 1956). One milliliter of properly diluted extract or glucose solution as the standard 
was added with $25 \mu \mathrm{L}$ of $80 \%$ (w/w) aqueous phenol solution and $2.5 \mathrm{~mL}$ of concentrated sulfuric acid. The mixture was thoroughly mixed and left in a $30^{\circ} \mathrm{C}$ water bath for 30 min. The total carbohydrate content was evaluated with a Shimadzu UV-1200 spectrophotometer at $490 \mathrm{~nm}$.

Total protein content The total protein content of the defatted rice bran extracts was evaluated in accordance to the Lowry-Folin assay (Lowry et al., 1951). An alkaline solution was prepared by dissolving $\mathrm{NaOH}(0.8 \mathrm{~g})$ and $\mathrm{Na}_{2} \mathrm{CO}_{3}$ $(4.0 \mathrm{~g})$ into distilled water $(200 \mathrm{~mL})$. Meanwhile, a copper reagent was prepared by dissolving $\mathrm{CuSO}_{4} \cdot 5 \mathrm{H}_{2} \mathrm{O}(0.05 \mathrm{~g})$ and trisodium citrate $(0.10 \mathrm{~g})$ into distilled water $(10 \mathrm{~mL})$. The mixture of $4 \mathrm{~mL}$ of the copper reagent and $200 \mathrm{~mL}$ of the alkaline solution was regarded as the alkaline copper reagent. Four tenths of a milliliter of a properly diluted extract was added with $2 \mathrm{~mL}$ of the alkaline copper reagent and allowed to react for $15 \mathrm{~min}$ at room temperature. The mixture was subsequently added with $0.2 \mathrm{~mL}$ of $50 \%(\mathrm{w} / \mathrm{w})$ aqueous Folin-Ciocalteu reagent and allowed to react for another 30 min. The total protein content was evaluated with the Shimadzu UV-1200 spectrophotometer at $750 \mathrm{~nm}$. The total protein content determined by this method also takes into account the degradation products of protein such as peptides and amino acids. The calibration curve was constructed using standard BSA solutions. Every extract was assayed at least in triplicate.

DPPH radical scavenging activity The DPPH radical scavenging activity of the defatted rice bran extracts was evaluated following the method reported by Fujinami et al. (2001) with some modifications. Approximately $39.4 \mathrm{mg}$ of DPPH was made up to $200 \mathrm{~mL}$ with ethanol. VC was dissolved and diluted with $50 \%(\mathrm{v} / \mathrm{v})$ aqueous ethanol to concentrations of 18 to $36 \mu \mathrm{M}$. The $\mathrm{VC}$ solutions were used as the standards for the preparation of the calibration curve. The extracts were also diluted with $50 \%(\mathrm{v} / \mathrm{v})$ aqueous ethanol to the proper concentrations. An aliquot of $0.8 \mathrm{~mL}$ of the VC solution or diluted extracts was added to $0.2 \mathrm{~mL}$ of the DPPH solution. After $30 \mathrm{~min}$ of reaction in the dark, the absorbance of the mixtures at $516 \mathrm{~nm}$, which corresponded to the remaining amounts of DPPH, was measured with the Shimadzu UV-1200 spectrophotometer. The radical scavenging activity of the extracts was defined as the amounts needed to reduce the initial DPPH concentration by $50 \%$. The radical scavenging activity of the extracts, which was expressed in the units of mmol-VC/g-bran, was determined from the following equation:

$$
\text { Radical scavenging activity }=(\mathrm{A}-\mathrm{B}+\mathrm{C}) / \mathrm{A} \times 100
$$

where A represents the absorbance of the mixture of $0.8 \mathrm{~mL}$ of $50 \%(\mathrm{v} / \mathrm{v})$ aqueous ethanol and $0.2 \mathrm{~mL}$ of the DPPH solu- tion, B represents the absorbance of the mixture of $0.8 \mathrm{~mL}$ of the $\mathrm{VC}$ solution or diluted extracts and $0.2 \mathrm{~mL}$ of the DPPH solution, and $\mathrm{C}$ represents the absorbance of the mixture of $0.8 \mathrm{~mL}$ of the diluted extracts and $0.2 \mathrm{~mL}$ of ethanol. The measurement was performed in triplicate.

Total phenolic content The total phenolic content of the defatted rice bran extracts was evaluated by using FolicCiocalteu reagent. A $100 \mu \mathrm{L}$ aliquot of the properly diluted extract was added into $400 \mu \mathrm{L}$ of a freshly prepared $10 \%(\mathrm{w} /$ w) Folin-Ciocalteu reagent aqueous solution and the mixture was kept for $5 \mathrm{~min}$ at room temperature. Subsequently, 1 $\mathrm{mL}$ of $7.5 \%(\mathrm{w} / \mathrm{v})$ aqueous $\mathrm{Na}_{2} \mathrm{CO}_{3}$ solution and $3.5 \mathrm{~mL}$ of distilled water were added. The absorbance of the mixtures at $765 \mathrm{~nm}$ was measured after $2 \mathrm{~h}$ of reaction in the dark at ambient temperature. Gallic acid used as the standard was prepared at the concentrations of 62.5 to $250 \mathrm{mg} / \mathrm{L}$ and the results were calculated as the gallic acid equivalent in the units of mg-gallic acid/g-bran.

Yield Fifty milliliters each of the defatted rice bran extracts was initially eliminated of water or solvent by rotary evaporation. The extracts were further dried in an oven (DNF-400, Yamato Scientific, Tokyo, Japan) at $105^{\circ} \mathrm{C}$ for $3 \mathrm{~h}$ and weighed after cooling to room temperature. The yield of extraction was presented in the units of $\mathrm{g} / \mathrm{g}$-bran.

Antioxidative ability against oxidation of linoleic acid The antioxidative ability of the defatted rice bran extracts was evaluated on the retardation effect upon oxidation of bulk linoleic acid by measuring the induction period based on the accelerated method (Wiboonsirikul et al., 2008a). All the apparatus were sufficiently cleaned to avoid any contamination that may affect the oxidation of the bulk linoleic acid. One gram of a $10 \%(\mathrm{w} / \mathrm{w})$ linoleic acid in methanol solution was weighed into each amber glass vial. The extracts of 40,80 , and $160 \mu \mathrm{L}$ were added to the linoleic acid solution, which are equivalent to $0.33,0.66$, and $1.32 \%(\mathrm{w} / \mathrm{w})$ of extract, respectively. The loaded amber glass vials were shaken gently to ensure thorough mixing of the solutions. The mixtures of methanol and water were evaporated under vacuum suction in a desiccator for $3 \mathrm{~h}$. The vessels were stoppered and placed into the Yamato Scientific DNF-400 oven at $110^{\circ} \mathrm{C}$. After the vessels were preheated for $5 \mathrm{~min}$, fresh air was pumped at the flow rate of $10 \mathrm{~L} / \mathrm{h}$ through each vessel into separate glass vials containing $50 \mathrm{~mL}$ of distilled water at $25^{\circ} \mathrm{C}$ using an Iwaki AP-032ZN air pump (Tokyo, Japan). The supplied fresh air provided oxygen required for oxidation of linoleic acid and brought along the resultant volatiles from the oxidation reaction, which were then trapped in the water. The conductance of the water was measured using an LCR-meter (AD-5827, A\&D, Tokyo, Japan). The time between the commencement of the experiment and the abrupt 
increase in conductance was defined as the induction period of oxidation.

\section{Results and Discussion}

Properties of the extracts from defatted rice bran The UV-Vis spectra were measured for the defatted rice bran extracts, prepared by $5-\mathrm{min}$ extractions with water and $20 \%(\mathrm{v} /$ v) aqueous ethanol at $237^{\circ} \mathrm{C}$. Both extracts showed absorption maxima at $281 \mathrm{~nm}$, suggesting the presence of various phenolic substances (Wiboonsirikul et al., 2007a). The UVVis spectrum of the extract from extraction with water alone was similar to that of the extract obtained with $20 \%(\mathrm{v} / \mathrm{v})$ aqueous ethanol (Fig. 2).

The extracts were subjected to HPLC analysis at the detection wavelength of $280 \mathrm{~nm}$ (Figs. 3a, 3b). Ferulic acid, the substance with antioxidative, antimicrobial, biological and therapeutic activities in rice bran (Garrote et al., 2004), was not detected. The compositions of the extracts were quite different from that of the rice bran extract reported by Tian et al. (2005). The variation may partly be attributed to the difference in methodology for extraction and analysis.

Effect of ethanol concentration Figure 4 shows changes of various properties of the defatted rice bran extracts that resulted from the increase in ethanol concentration of the extraction medium. With the increase in ethanol concentration of up to $30 \%(\mathrm{v} / \mathrm{v})$, the total carbohydrate content of the extract decreased slightly from 0.052 to $0.035 \mathrm{~g} / \mathrm{g}$-bran, while the total protein content increased from 0.253 to 0.312 g/g-bran. The total phenolic content increased from 44.4 to $53.5 \mathrm{mg}$-gallic acid/g-bran up to the ethanol concentration of

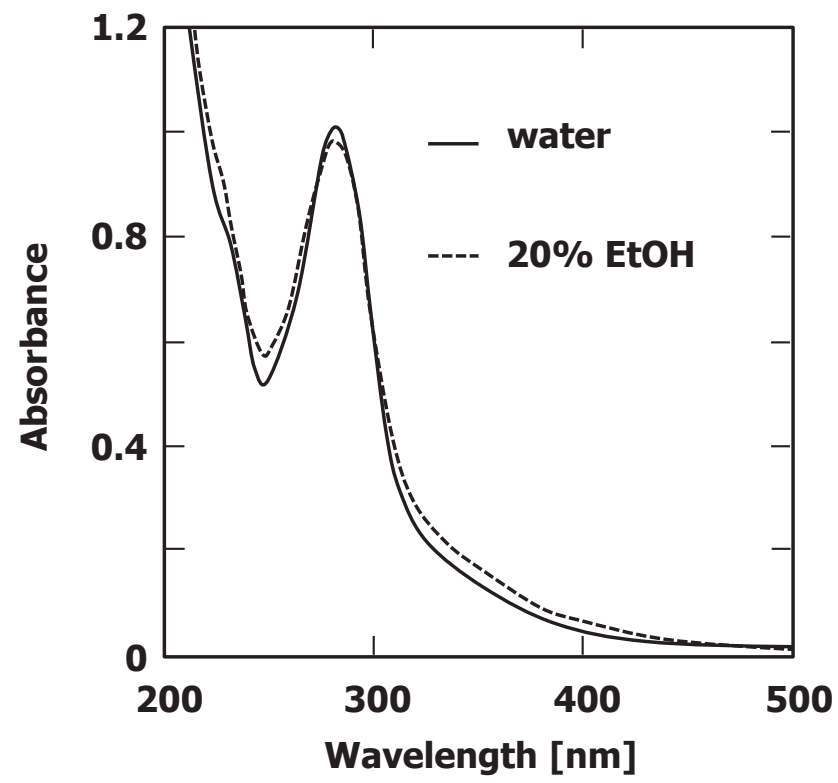

Fig. 2. UV-Vis spectra of the extracts obtained by 5-min extractions with water (solid curve) and $20 \%(\mathrm{v} / \mathrm{v})$ aqueous ethanol (broken curve) at $237^{\circ} \mathrm{C}$.

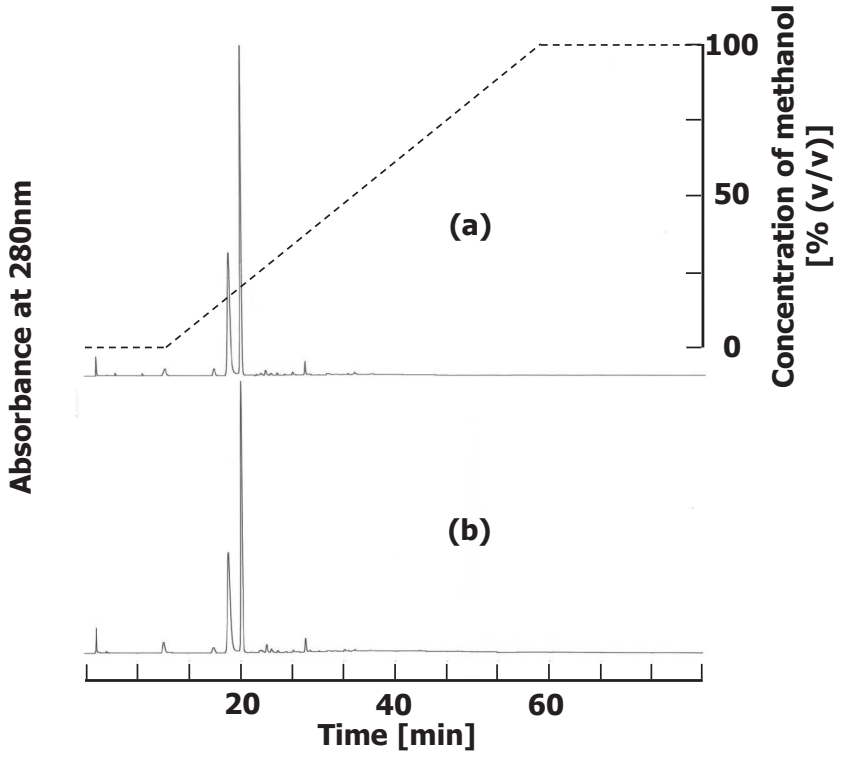

Fig. 3. HPLC chromatograms of the extracts obtained by 5-min extractions with (a) water and (b) $20 \%$ (v/v) aqueous ethanol at $237^{\circ} \mathrm{C}$

$20 \%(\mathrm{v} / \mathrm{v})$, which was almost the same as the value of 53.3 mg-gallic acid/g-bran of the extract obtained with $30 \%$ (v/ v) aqueous ethanol. These results indicate that the phenolic compounds of defatted rice bran were efficiently extracted with 20\% (v/v) aqueous ethanol. The DPPH radical scavenging activity of the extracts also increased from 0.142 to 0.230 $\mathrm{mmol}-\mathrm{VC} / \mathrm{g}$-bran, with the increase in ethanol concentration of up to $30 \%(\mathrm{v} / \mathrm{v})$. The yield of extraction, ranging from 0.398 to $0.431 \mathrm{~g} / \mathrm{g}$-bran, would be close to the sum of total carbohydrate, protein, and phenolic contents from 0.343 $0.402 \mathrm{~g} / \mathrm{g}$-bran. The slight difference between the yield and

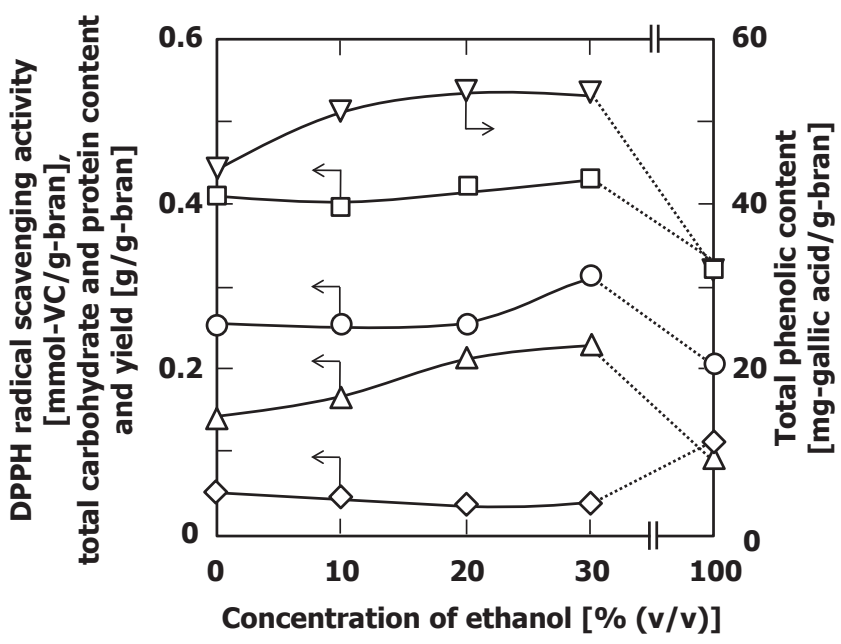

Fig. 4. Total carbohydrate content $(\diamond)$, DPPH radical scavenging activity $(\triangle)$, total protein content $(\bigcirc)$, yield $(\square)$, and total phenolic content $(\nabla)$ of the extracts obtained from defatted rice bran treated at various ethanol concentrations at $237^{\circ} \mathrm{C}$ for $5 \mathrm{~min}$. 
the sum would be ascribed to the difference in the composition among the samples obtained at different temperatures, although the total carbohydrate, protein, and phenolic contents were determined using glucose, BSA and gallic acid for all the samples. When ethanol alone was used as the extraction medium, the total carbohydrate content increased to 0.111 g/g-bran, whereas the total protein content and yield were found to decrease to 0.206 and $0.321 \mathrm{~g} / \mathrm{g}$-bran, respectively. The decrease in total phenolic content to $31.9 \mathrm{mg}$-gallic acid/ g-bran also led to the lowering of the DPPH radical scavenging activity to $0.092 \mathrm{mmol}-\mathrm{VC} / \mathrm{g}$-bran.

Effect of extraction time The $20 \%(\mathrm{v} / \mathrm{v})$ aqueous ethanol was chosen as the extraction medium to study the effect of extraction time. The selection was done based on the high phenolic content and high DPPH radical scavenging activity of the corresponding extracts.

The defatted rice bran was treated with water or $20 \%(\mathrm{v} / \mathrm{v})$ aqueous ethanol at $237^{\circ} \mathrm{C}$ for different extraction times. The total carbohydrate content of the extracts gradually decreased with extended extraction time (Fig. 5a). This would be attributed to the decomposition or degradation of saccharides. The reaction was led by the high ion product of water at high temperatures and also the fact that the reaction products do not respond to the phenol-sulfuric method (Hata et al., 2008).

The total protein content also decreased with extended extraction time (Fig. 5a). At high temperatures, the peptide bonds of proteins were hydrolyzed and the resultant free amino acids were further transformed and decomposed into other substances (Abdelmoez et al., 2007; Rogalinski et al., 2008). These substances, presumably ammonia and organic acids resulting from deamination as well as carbonic acids and amines from decarboxylation (Sato et al., 2004), do not respond to the Lowry-Folin method (Lowry et al., 1951). The total phenolic content of the extracts obtained by extraction with aqueous ethanol was higher than that of the extract obtained with water (Fig. 5b). This might have resulted from the higher hydrophobicity of the $20 \%(\mathrm{v} / \mathrm{v})$ aqueous ethanol compared to that of water, especially when the extraction medium returned to ambient conditions from subcritical conditions. The phenolic content of the extracts not only affected their radical scavenging activity, but also their antioxidative activity (Sroka and Cisowski, 2003). The extract obtained by 10 -min extraction with $20 \%(\mathrm{v} / \mathrm{v})$ aqueous ethanol recorded the highest phenolic content of $62.6 \mathrm{mg}$-gallic acid/g-bran, but showed lower DPPH radical scavenging activity of 0.197 mmol-VC/g-bran compared to that of the extract obtained by 5 -min extraction with the same extraction medium. The highest DPPH radical scavenging activity of $0.261 \mathrm{mmol}-$ $\mathrm{VC} / \mathrm{g}$-bran was given by the extract obtained by 10 -min extraction with water, with the yield of extraction of 0.494

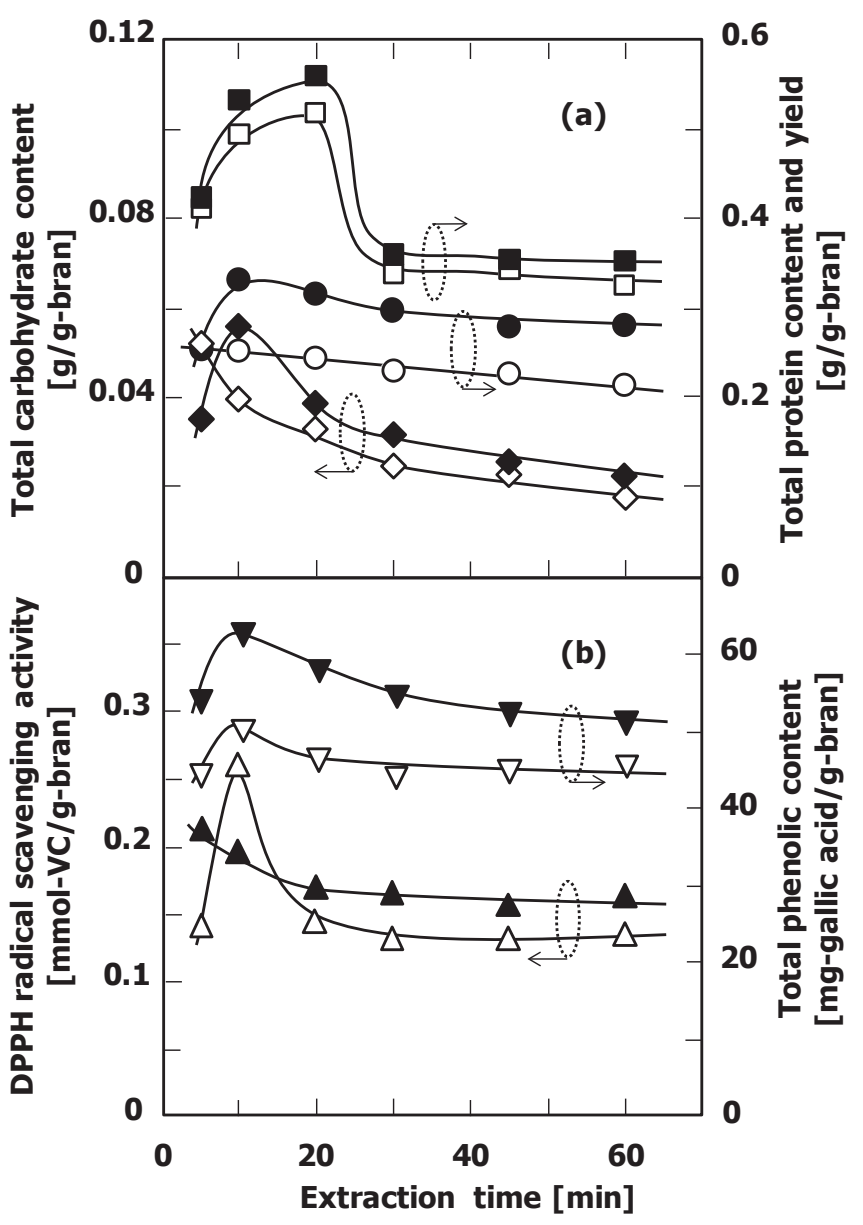

Fig. 5. (a) Total carbohydrate content $(\diamond, \diamond)$, total protein content $(\boldsymbol{O}, \bigcirc)$, yield $(\boldsymbol{\square}, \square)$, (b) DPPH radical scavenging activity $(\boldsymbol{\Delta}, \triangle)$, and total phenolic content $(\boldsymbol{\nabla}, \nabla)$ of the extracts from defatted rice bran treated for different extraction times at $237^{\circ} \mathrm{C}$ with water (open symbol) and $20 \%$ (v/v) aqueous ethanol (closed symbol).

g/g-bran. The amounts of functional substances in the extracts were not always proportional to the yield of extraction. Therefore, when the yield was taken into consideration, the DPPH radical scavenging activity of the extract obtained by 10 -min extraction with water could be presented as 0.528 mmol-VC/g-extract, which was close to the $0.509 \mathrm{mmol}-\mathrm{VC} /$ g-extract of the extract from the 5-min extraction with $20 \%$ $(\mathrm{v} / \mathrm{v})$ aqueous ethanol. Similarly, the total phenolic content of the extract from 5-min extraction with $20 \%$ (v/v) aqueous ethanol was $126.8 \mathrm{mg}$-gallic acid/g-extract, which was about $25 \%$ higher than that of the extract obtained by 10 -min extraction with subcritical water. Based on the radical scavenging activity and phenolic content of the extracts, efficiency in terms of extraction time, and the reduction in the use of organic solvents, the extraction medium of $20 \%$ (v/v) aqueous ethanol and the extraction time of $5 \mathrm{~min}$ are identified as the optimal extraction conditions.

Effect of extraction temperature As shown in Fig. 6, the total carbohydrate content increased with increasing extrac- 
tion temperature until $207^{\circ} \mathrm{C}$, and lowered at $237^{\circ} \mathrm{C}$. During extraction, carbohydrates such as cellulose would be further hydrolyzed to the constituent sugars (Bobleter, 1994). With the elevated ion products at high temperatures, the released sugars such as glucose, fructose, and oligomers (cellobiose, cellotriose, cellotetraose, etc.) were subsequently either converted to 5-hydroxymethyl-2-furfural (5-HMF) (Khajavi et al., 2005) or decomposed to corresponding smaller species of acids, aldehydes, and alcohols of $1-3$ carbons (Sasaki et al., 1998).

The total protein content increased sharply until $207^{\circ} \mathrm{C}$, reaching the value of $0.227 \mathrm{~g} / \mathrm{g}$-bran. Predicting by extrapolation, the total protein content at $237^{\circ} \mathrm{C}$ was expected to exceed $0.3 \mathrm{~g} / \mathrm{g}$-bran. Nevertheless, the increase was less pronounced, presumptively due to the degradation of protein that took place simultaneously with the extraction, producing amino acids which give less color than the protein with the Folin-Ciocalteu reagent (Lowry et al., 1951).

The total carbohydrate content decreased faster than the total protein content mainly due to the fact that the peptide bonds in proteins exhibited a much higher stability compared to the glycosidic linkages (Rogalinski et al., 2008). The decomposition activation energy of amino acids was similar to that of monosaccharides, ranging between 150 and $200 \mathrm{~kJ} /$ mol (Sato et al., 2004; Usuki et al., 2008).

The decrease in yield of extraction from $0.537 \mathrm{~g} / \mathrm{g}$-bran at $207^{\circ} \mathrm{C}$ to $0.422 \mathrm{~g} / \mathrm{g}$-bran at $237^{\circ} \mathrm{C}$ was caused by the diminution of the total carbohydrate content at high temperatures that outbalanced the increase in the total protein and phenolic contents. The phenolic compounds in rice bran were bound to hemicellulose, cellulose, and lignin in the cell wall, and

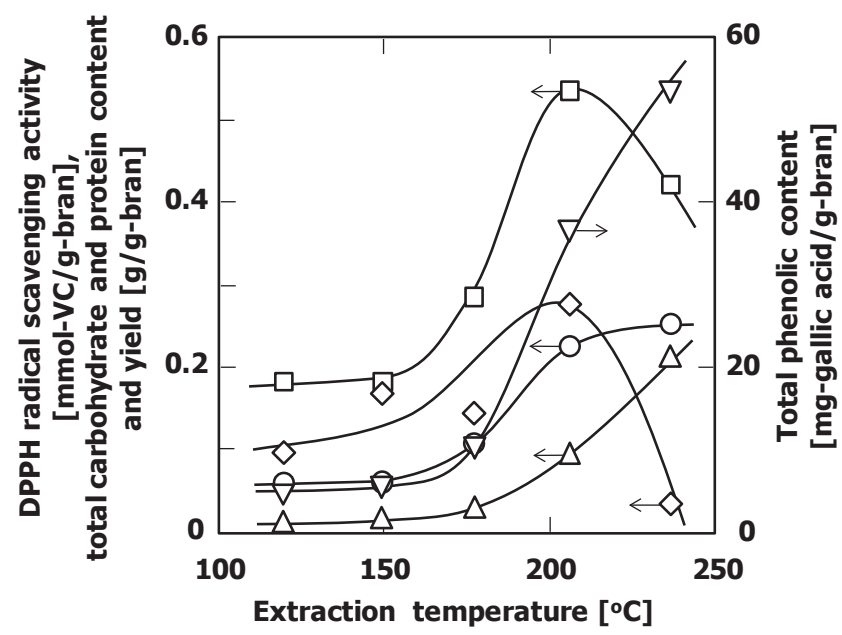

Fig. 6. DPPH radical scavenging activity, total carbohydrate content, total protein content, yield, and total phenolic content of the extracts from defatted rice bran treated at different extraction temperatures for $5 \mathrm{~min}$ with $20 \%(\mathrm{v} / \mathrm{v})$ aqueous ethanol. The symbols are the same as those in Fig. 4. were difficult to dissolve into the extraction medium unless the lignocellulosic materials were hydrolyzed under subcritical conditions (Garrote et al., 2004), thus explaining the increase of total phenolic content with increasing extraction temperature. The DPPH radical scavenging activity is closely related to the phenolic contents (Rice-Evans et al., 1997). The DPPH radical scavenging activity of the extracts showed increasing trends with the increase in total phenolic content.

When presented on yield basis, a satisfactory linear correlation between the DPPH radical scavenging activity and total phenolic content with a correlation coefficient, $R^{2}$ of 0.9994, was obtained until $207^{\circ} \mathrm{C}$, after which the DPPH radical scavenging activity deflected significantly upward from the curvilinear relationship (Fig. 7). The products resulting from Maillard reaction may possibly be responsible for this unforeseen phenomenon (Morales and Jiménez-Pérez, 2001; Murakami et al., 2002).

\section{Antioxidative ability against oxidation of linoleic acid}

The changes in conductance of the distilled water used to trap the volatiles resulting from oxidation of the bulk linoleic acid were monitored. The inflection point in the conductance curve was defined as the induction period of oxidation and the prolongation of induction period in comparison to the negative control shows the antioxidative ability of the extract. The bulk linoleic acid was added with the bran extract obtained by 5 -min extraction with either water or $20 \%(\mathrm{v} / \mathrm{v})$ aqueous ethanol at $237^{\circ} \mathrm{C}$. In Fig. 8, all the treatments added with the extracts showed a longer induction period compared to the negative control.

The induction period prolonged proportionally to the

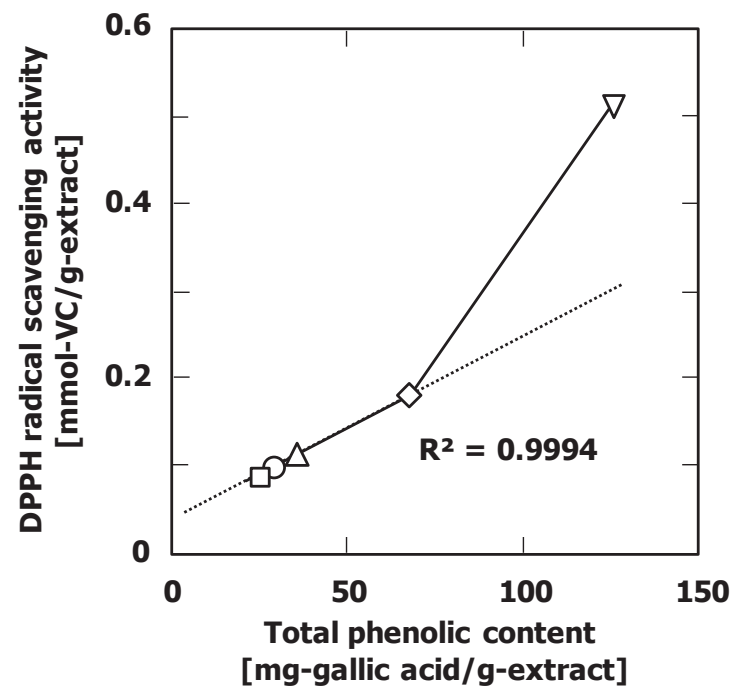

Fig. 7. Correlation between DPPH radical scavenging activity and total phenolic content of the extracts from defatted rice bran treated at different extraction temperatures $\left(120^{\circ} \mathrm{C}: \square, 150^{\circ} \mathrm{C}: \bigcirc, 178^{\circ} \mathrm{C}\right.$ : $\triangle, 207^{\circ} \mathrm{C}: \diamond$, and $\left.237^{\circ} \mathrm{C}: \nabla\right)$ for $5 \mathrm{~min}$ with $20 \%(\mathrm{v} / \mathrm{v})$ aqueous ethanol. 


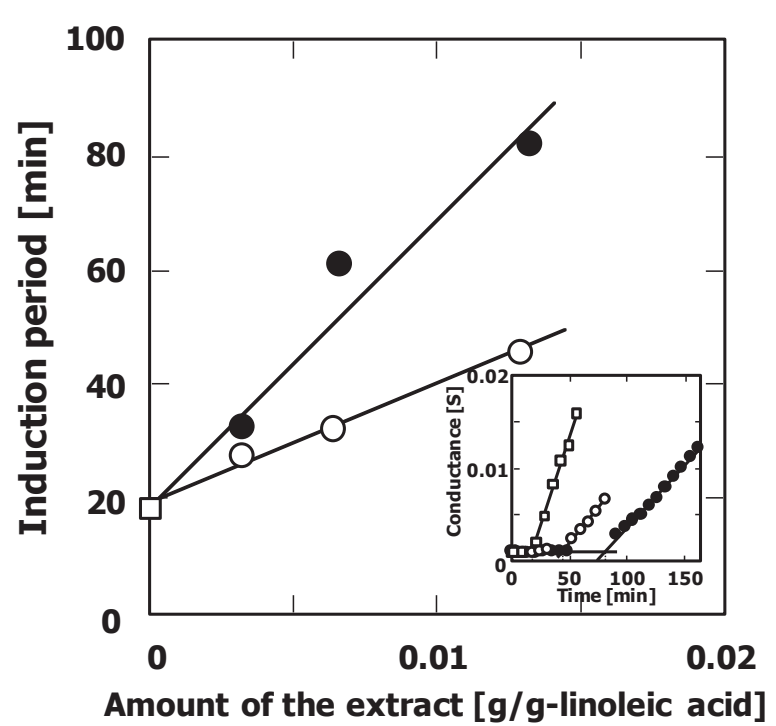

Fig. 8. Induction period of oxidation reaction of bulk linoleic acid added with the extracts obtained by 5 -min extractions with water $(\bigcirc)$ and $20 \%$ (v/v) aqueous ethanol (O). In the negative control ( $\square$ ), distilled water was added in place of the extracts. The inset figure shows the changes in the conductance of water for bulk linoleic acid added with $1.32 \%(\mathrm{w} / \mathrm{w})$ of extracts.

amount of extracts added as shown in Fig 8. Furthermore, the extract obtained with $20 \%(\mathrm{v} / \mathrm{v})$ aqueous ethanol exhibited better antioxidative ability than that obtained by subcritical water extraction. The induction period of the negative control treatment was $18.7 \mathrm{~min}$, and that of the treatment added with $1.32 \%(\mathrm{w} / \mathrm{w})$ of the extract obtained by subcritical water extraction was $45.6 \mathrm{~min}$. With the addition of $1.32 \%(\mathrm{w} /$ w) of the extract obtained with $20 \%(\mathrm{v} / \mathrm{v})$ aqueous ethanol, the induction period was lengthened to $81.6 \mathrm{~min}$, which was almost $80 \%$ longer than that achieved by the treatment added with the extract obtained by subcritical water extraction.

\section{Conclusions}

The subcritical extraction using aqueous ethanol as the extraction medium was studied on defatted rice bran. The DPPH radical scavenging activity and total phenolic content of the extracts increased with ethanol concentration up to $30 \%(\mathrm{v} / \mathrm{v})$. The ethanol concentration of $20 \%(\mathrm{v} / \mathrm{v})$ was further studied because of its ability to produce extracts with high DPPH radical scavenging activity and total phenolic content. Extraction time is one of the measures to evaluate the efficiency of an extraction method. Subcritical extraction for an extraction time of 5 min using $20 \%(\mathrm{v} / \mathrm{v})$ aqueous ethanol as the extraction medium was shown to be satisfactorily efficient. With increasing extraction temperature, the DPPH radical scavenging activity and total phenolic content increased linearly until $207^{\circ} \mathrm{C}$. Some substances which enhanced the DPPH radical scavenging activity may be pro- duced at $237^{\circ} \mathrm{C}$. The optimal extraction could be achieved by using $20 \%(\mathrm{v} / \mathrm{v})$ aqueous ethanol as the extraction medium for an extraction time of $5 \mathrm{~min}$ at an extraction temperature of $237^{\circ} \mathrm{C}$. The extract obtained under these conditions showed better antioxidative ability than the extract obtained by subcritical water extraction. The antioxidative ability of the defatted rice bran extracts to suppress oxidation of bulk linoleic acid suggests the feasibility of direct application of the extracts to oil-rich foods.

Acknowledgements This study is financially supported by the Cooperation for Innovative Technology and Advanced Research in Evolution Area (CITY AREA) program from the Ministry of Education, Culture, Sports, Science and Technology, Japan. The first author (T.-Y. Chiou) greatly appreciates the scholarship from the Interchange Association, Japan.

\section{References}

Abdelmoez, W., Nakahasi, T. and Yoshida, H. (2007). Amino acid transformation and decomposition in saturated subcritical water conditions. Ind. Eng. Chem. Res., 46, 5286-5294.

Abdul-Hamid, A. and Luan, Y.S. (2000). Functional properties of dietary fibre prepared from defatted rice bran. Food Chem., 68 , 15-19.

Ambrose, D., Sprake, C.H.S. and Townsend, R. (1975). Thermodynamic properties of organic oxygen compounds .37. Vaporpressures of methanol, ethanol, pentan-1-ol, and octan-1-ol from normal boiling temperature to critical-temperature. J. Chem. Thermodyn., 7, 185-190.

AOCS (1979). "Official and Tentative Methods of the American Oil Chemists' Society”, 3rd ed., American Oil Chemists' Society, Champaign, IL.

Bobleter, O. (1994). Hydrothermal degradation of polymers derived from plants. Progr. Polym. Sci., 19, 797-841.

Castelluccio, C., Paganga, G., Melikian, N., Bolwell, G.P., Pridham, J., Sampson, J. and Riceevans, C. (1995). Antioxidant Potential of Intermediates in Phenylpropanoid Metabolism in HigherPlants. FEBS Lett., 368, 188-192.

Chung, H.S. and Woo, W.S. (2001). A quinolone alkaloid with antioxidant activity from the aleurone layer of anthocyanin-pigmented rice. J. Nat. Prod., 64, 1579-1580.

Cuvelier, M.-E., Richard, H. and Berset, C. (1992). Comparison of the antioxidative activity of some acid-phenols - structure activity relationship. Biosci. Biotech. Biochem., 56, 324-325.

Dubois, M., Gilles, K.A., Hamilton, J.K., Rebers, P.A. and Smith, F. (1956). Colorimetric method for determination of sugars and related substances. Anal. Biochem., 28, 350-356.

Fujinami, Y., Tai, A. and Yamamoto, I. (2001). Radical scavenging activity against 1,1-diphenyl-2-picrylhydrazyl of ascorbic acid 2-glucoside (AA-2G) and 6-acyl-AA-2G. Chem. Pharm. Bull., 
49, 642-644.

Garrote, G., Cruz, J.M., Moure, A., Dominguez, H. and Parajo, J.C. (2004). Antioxidant activity of byproducts from the hydrolytic processing of selected lignocellulosic materials. Trends Food Sci. Technol., 15, 191-200.

Graf, E. (1992). Antioxidant potential of ferulic acid. Free Radical Bio. Med., 13, 435-448.

Gude, M. and Teja, A.S. (1995). Vapor-liquid critical properties of elements and compounds. 4. Aliphatic alkanols. J. Chem. Eng. Data, 40, 1025-1036.

Han, B.S., Park, C.B., Takasuka, N., Naito, A., Sekine, K., Nomura, E., Taniguchi, H., Tsuno, T. and Tsuda, H. (2001). A ferulic acid derivative, ethyl 3-(4'-geranyloxy-3-methoxyphenyl)-2- propenoate, as a new candidate chemopreventive agent for colon carcinogenesis in the rat. Jpn. J. Cancer Res., 92, 404-409.

Hata, S., Wiboonsirikul, J., Maeda, A., Kimura, Y. and Adachi, S. (2008). Extraction of defatted rice bran by subcritical water treatment. Biochem. Eng. J., 40, 44-53.

Herrero, M., Cifuentes, A. and Ibañez, E. (2006). Sub- and supercritical fluid extraction of functional ingredients from different natural sources: plants, food-by-products, algae and microalgae A review. Food Chem., 98, 136-148.

Hirosaka, K., Fukayama, M., Wakamatsu, K., Ishida, Y., Kitagawa, K. and Hasegawa, T. (2007). Combustion of ethanol by hydrothermal oxidation. Proc. Combust. Inst., 31, 3361-3367.

Hirosaka, K., Koido, K., Fukayama, M., Ouryoji, K. and Hasegawa, T. (2008). Experimental and numerical study of ethanol oxidation in sub-critical water. J. Supercrit. Fluids, 44, 347-355.

Iqbal, S., Bhanger, M.I. and Anwar, F. (2005). Antioxidant properties and components of some commercially available varieties of rice bran in Pakistan. Food Chem., 93, 265-272.

Kaneda, I., Iwai, K., Kubo, H. and Sakurai, H. (2004). Antioxidative properties of extracts from ancient rice brans. Food Sci. Technol. Res., 10, 374-382.

Khajavi, S.H., Kimura, Y., Oomori, R., Matsuno, R. and Adachi, S. (2005). Degradation kinetics of monosaccharides in subcritical water. J. Food Eng., 68, 309-313.

Khajavi, S.H., Ota, S., Kimura, Y. and Adachi, S. (2006). Kinetics of maltooligosaccharide hydrolysis in subcritical water. J. Agric. Food Chem., 54, 3663-3667.

Kim, H.J., Lee, S.B., Park, K.A. and Hong, I.K. (1999). Characterization of extraction and separation of rice bran oil rich in EFA using SFE process. Sep. Purif. Technol., 15, 1-8.

Lowry, O.H., Rosebrough, N.J., Farr, A.L. and Randall, R.J. (1951). Protein measurement with the Folin phenol reagent. J. Biol. Chem., 193, 265-275.

Miller, D.J. and Hawthorne, S.B. (2000). Solubility of liquid organic flavor and fragrance compounds in subcritical (hot/liquid) water from 298 K to 473 K. J. Chem. Eng. Data, 45, 315-318.

Morales, F.J. and Jiménez-Pérez, S. (2001). Free radical scavenging capacity of Maillard reaction products as related to colour and fluorescence. Food Chem., 72, 119-125.

Murakami, M., Shigeeda, A., Danjo, K., Yamaguchi, T., Takamura, H. and Matoba, T. (2002). Radical-scavenging activity and brightly colored pigments in the early stage of the Maillard reaction. J. Food Sci., 67, 93-96.

Pourali, O., Asghari, F.S. and Yoshida, H. (2009). Sub-critical water treatment of rice bran to produce valuable materials. Food Chem., 115, 1-7.

Rice-Evans, C.A., Miller, N.J. and Paganga, G. (1997). Antioxidant properties of phenolic compounds. Trends Plant Sci., 2, 152-159.

Rogalinski, T., Herrmann, S. and Brunner, G. (2005). Production of amino acids from bovine serum albumin by continuous subcritical water hydrolysis. J. Supercrit. Fluids, 36, 49-58.

Rogalinski, T., Liu, K., Albrecht, T. and Brunner, G. (2008). Hydrolysis kinetics of biopolymers in subcritical water. J. Supercrit. Fluids, 46, 335-341.

Sasaki, M., Kabyemela, B., Malaluan, R., Hirose, S., Takeda, N., Adschiri, T. and Arai, K. (1998). Cellulose hydrolysis in subcritical and supercritical water. J. Supercrit. Fluids, 13, 261-268.

Sasaki, M., Fang, Z., Fukushima, Y., Adschiri, T. and Arai, K. (2000). Dissolution and hydrolysis of cellulose in subcritical and supercritical water. Ind. Eng. Chem. Res., 39, 2883-2890.

Sato, N., Quitain, A.T., Kang, K., Daimon, H. and Fujie, K. (2004). Reaction kinetics of amino acid decomposition in high-temperature and high-pressure water. Ind. Eng. Chem. Res., 43, $3217-$ 3222.

Sroka, Z. and Cisowski, W. (2003). Hydrogen peroxide scavenging, antioxidant and anti-radical activity of some phenolic acids. Food Chem. Toxicol., 41, 753-758.

Tian, S., Nakamura, K., Cui,T. and Kayahara, H. (2005). Highperformance liquid chromatographic determination of phenolic compounds in rice. J. Chromatogr. A, 1063, 121-128.

Usuki, C., Kimura, Y. and Adachi, S. (2008). Degradation of pentoses and hexouronic acids in subcritical water. Chem. Eng. Technol., 31, 133-137.

Watchararuji, K., Goto, M., Sasaki, M. and Shotipruk, A. (2008). Value-added subcritical water hydrolysate from rice bran and soybean meal. Bioresource Technol., 99, 6207-6213.

Wiboonsirikul, J., Kimura, Y., Kadota, M., Morita, H., Tsuno, T. and Adachi, S. (2007a). Properties of extracts from defatted rice bran by its subcritical water treatment. J. Agric. Food Chem., 55, 8759-8765.

Wiboonsirikul, J., Hata, S., Tsuno, T., Kimura, Y. and Adachi, S. (2007b). Production of functional substances from black rice bran by its treatment in subcritical water. LWT-Food Sci. Technol., 40, 1732-1740.

Wiboonsirikul, J., Nakazawa, R., Kobayashi, T., Morita, H., Tsuno, T. and Adachi, S. (2008a). Suppression of the oxidation of methyl linoleate encapsulated with the extract from defatted rice bran by 
a compressed hot water treatment. Eur. Food Res. Technol., 228 , 109-114.

Wiboonsirikul, J., Kimura, Y., Kanaya, Y., Tsuno, T. and Adachi, S. (2008b). Production and characterization of functional substances from a by-product of rice bran oil and protein production by a compressed hot water treatment. Biosci. Biotech. Biochem., 72, 384-392. 